\title{
Caracterização do pescador e da frota pesqueira comercial de Manoel Urbano e Sena Madureira (AC) e Boca do Acre (AM)
}

\section{Gfisherman and the fishing fleet of the municipalities of Manoel Urbano and Sena Madureira (AC) and Boca do Acre (AM) in Brazil}

Oriana Trindade de Almeida - Doutora em Ciências Ambientais. Professora Adjunta do NAEA/ UFPA. E-mail: oriana@ufpa.br

Luciene Amaral-Advogada IPAM. E-mail: luciene@ipam.org.br

Sérgio Rivero - Doutor em Ciências Socioambientais, mestre em Engenharia de Produção. E-mail: rivero@ufpa.br

Christian Nunes da Silva - Mestre em Geografia - CFCH/UFPA. Pesquisador do GAPTA/UFPA. Professor da Faculdade de Geografia e Cartografia da UFPA. E-mail: cnunes@ufpa.br

\section{Resumo}

Vários estudos sobre o setor pesqueiro têm sido feitos na região amazônica, entretanto, a maior parte se concentra em regiões próximas à calha do rio do Amazonas e sua foz. Este trabalho foi voltado para caracterização da pesca no rio Purus, frota pesqueira comercial e do pescador em três municípios pesquisados nas margens desse rio, estimando, assim, a produção e a renda da frota pesqueira naquela região. Os resultados mostram que em Manoel Urbano (AC) predomina a pesca de lagos, enquanto que Sena Madureira (AC) os ambientes de pesca são mais diversificados, com registros de pesca em lagos, rios e igarapés. Em Boca do Acre (AM) prevalece a pesca no rio Purus, principalmente na área dos municípios de Pauiní e Lábrea. Quanto ao tipo de embarcação utilizada, em Manoel Urbano a pesca é praticada somente em canoas, sendo que um pequeno percentual corresponde a canoas sem motor, enquanto que em Sena Madureira a maioria dos pescadores pesca de canoas e alguns utilizam barco motor; já em Boca do Acre a pesca é praticada basicamente de barcos, sendo menor o número de canoas motorizadas. Em relação aos custos da viagem, a análise mostrou que os custos variáveis representam $63 \%$ da receita dos pescadores de canoa e $76 \%$ da receita total dos barcos de pesca. A análise também mostra que pescadores de canoa motorizada apresentaram maior capacidade produtiva por unidade de esforço em relação aos pescadores de barcos.

\section{Palavras-chave}

Pesca. Frota Pesqueira. Amazônia. Rio Purus.

\begin{abstract}
Several studies about the fishing sector have been carried on in the Amazon, however, the majority of these studies are concentrated on regions near the Amazon river bank and its delta. This work has the objective to characterize the Purus commercial fishing fleet and the fisher in three counties: Manoel Urbano and Sena Madureira in the Brazilian state of Acre (AC) and Boca do Acre, in Amazonas (AM).We estimate the fisheries production and income. The results show that in Manoel Urbano (AC) lake fisheries predominate while in Sena Madureira (AC), the diversity in fishing places are lager with fishers using lakes, river and creeks. In Boca do Acre (AM), the largest among the three cities, the most important fishing plots are Pauini and Labrea areas. In relation to boats, Manoel Urbano fishers use only canoes with most of it motorized. In Boca do Acre, fisheries are practiced mainly in boat. In relation to fishing trip costs the results showed that variable costs are the main costs for canoes (63\% of total income) and boats (73\% of total income). The analyses showed also that motorized canoes have larger productive capacity per unit of effort (CPUE) in relation to boats.
\end{abstract}

\section{Keywords}

Fisheries. Commercial fleet. Amazon. Purus River. 


\section{INTRODUÇÃO}

A pesca na Amazônia tem se tornado uma atividade cada vez mais importante para a região, sendo responsável por $25 \%$ da produção nacional de pescado. O Pará e o Amazonas são os maiores produtores de pescado da Região Norte, sendo que $70 \%$ da produção do estado do Pará e 30\% da produção do estado do Amapá corresponde à pesca marinha (ALMEIDA; MCGRATH; RUFFINO, 2001; ALMEIDA; LORENZEN; MCGRATH, 2003, 2004, 2009; IBAMA, 2000, 2001). Os estados do Acre, Amazonas, Rondônia, Roraima e Tocantins têm $100 \%$ da sua produção voltada para a pesca continental (ALMEIDA; LORENZEN; MCGRATH, 2004; IBAMA, 2001).

Nos últimos 40 anos, o governo brasileiro buscou implementar políticas e projetos de infraestrutura voltados para o desenvolvimento e integração econômica da região amazônica com o resto do país. As políticas regionais de integração nacional estimularam a migração para a Amazônia, o que resultou num crescimento dos mercados urbanos por peixe fresco. Paralelamente, o governo concedeu incentivos para a construção de grandes frigoríficos voltados para os mercados de outras regiões brasileiras e para a exportação. Essas mudanças fizeram com que a pesca na Amazônia deixasse de ser uma atividade sazonal, limitada à produção de peixe seco e salgado para população local, durante o período de seca do rio, para ser uma atividade anual, produtora de peixe fresco e congelado, voltada para vários mercados, inclusive para exportação para outros estados do Brasil e para o exterior (MCGRATH et al., 1993). Neste sentido, durante as décadas de 1970 e 1980 houve uma grande expansão da pesca comercial na região amazônica. Atualmente, os pescadores comerciais viajam longas distâncias dos centros urbanos até as principais áreas de pesca, de modo que praticamente toda a bacia amazônica passou a ser explorada (ALMEIDA; MCGRATH; RUFFINO, 2001; ALMEIDA; LORENZEN; MCGRATH, 2003, 2009).

Essa transição também só foi possível devido à simultânea introdução de novas tecnologias, como o motor a diesel, as redes de fibra sintética, o gelo e a tecnologia de armazenagem, inovações essas que tornaram viáveis as viagens de longa distância, proporcionando maior capacidade de captura e armazenagem de peixe, que passou, então, a ser comercializado fresco nos mercados urbanos. Desse modo, a expansão e a intensificação da pesca comercial acabaram por mudar os tipos de produtos pesqueiros e as características do pescador comercial, com isso, tais mudanças aumentaram a pressão sobre os estoques de pescado e acentuaram a disputa entre pescadores pelos lagos de várzea. 
Por esses motivos, as comunidades de várzea em toda a região têm tentado controlar seus lagos adjacentes, por meio da regulamentação de sua pesca, onde o Instituto Brasileiro do Meio Ambiente e dos Recursos Naturais Renováveis (IBAMA), a instituição federal responsável pelo manejo comunitário, passou a reconhecer a legitimidade dos chamados acordos de pesca (RASEIRA, 2007; D'ALMEIDA, 2006; RUFFINO, 2005; SILVA; BEGOSSI, 2004). Em função disso, na última década, o IBAMA, as Colônias de Pescadores, as comunidades de várzea, organizações ligadas à Igreja e Organizações Não Governamentais (ONGs) têm trabalhado no desenvolvimento de um sistema de comanejo que incorpore os acordos de pesca à estrutura formal do manejo pesqueiro em regiões de lagos.

Vários estudos sobre o setor pesqueiro têm sido feitos na região amazônica, entretanto, a maior parte se concentra em regiões próximas à calha do rio do Amazonas. O rio Purus, que nasce no Peru a aproximadamente $500 \mathrm{~m}$ de altitude, percorre cerca de $3.300 \mathrm{~km}$ até a foz e apresenta um percurso bastante sinuoso e curvas bem fechadas. Sua importância está principalmente no abastecimento de sua região de influência, no entanto, poucos estudos sobre a frota pesqueira têm sido desenvolvidos na região do rio Purus e no estado do Acre.

Neste contexto, o Projeto Alto Purus, iniciativa do Governo do Estado do Acre, executado por meio da Secretaria de Assistência Técnica e Extensão Agroflorestal (SEATER/AC), foi implementado em 2001, para promover a discussão com os setores ligados à pesca na região. A proposta do Projeto Alto Purus foi de promover a discussão dos grupos usuários dos recursos pesqueiros, a fim de torná-los agentes participativos na elaboração e implementação de políticas públicas e na gestão dos recursos pesqueiros no Estado. Em 2002, por meio de uma parceria com a WWF-Brasil, o projeto consolidou suas ações, promovendo fóruns e oficinas sobre manejo e educação ambiental junto às comunidades da região, estabelecendo um trabalho de estatística pesqueira nos portos de desembarque dos municípios de Sena Madureira, Manoel Urbano e Boca do Acre, áreas de atuação do projeto. Esse artigo é resultado dessa pesquisa e tem objetivo de caracterizar a pesca e a frota pesqueira comercial nos três municípios. 


\section{METODOLOGIA}

\subsection{CARACTERIZAÇÃO DO DESEMBARQUE PESQUEIRO}

Essa pesquisa é baseada em duas fontes de dados: dados de 469 desembarques coletados pela SEATER durante o ano de 2004, e dados das entrevistas, a partir de uma amostra desses pescadores, com o objetivo de caracterizar econômica e socialmente os pescadores representativos dos diferentes tipos de embarcações de pesca que desembarcaram peixe nas cidades estudadas, durante os meses de outubro e novembro de 2005.

A pesca foi caracterizada para todo o ano, com base no banco de dados de estatística pesqueira da SEATER, onde os dados de desembarque, utilizados para caracterizar a frota das três cidades, foram coletados diariamente durante o ano de 2004. As entrevistas foram feitas por três técnicos, localizados nos principais pontos de desembarque de peixe, nos horários de pico de desembarques, um em cada cidade. As informações foram coletadas por meio de entrevistas sobre as características das embarcações e da viagem de pesca, incluindo: origem da embarcação, volume pescado por espécie de peixe, número de pescadores e canoas, dias de pesca, quantidade de gelo levado, quantidade de combustível consumido e o preço da primeira comercialização do peixe.

\subsection{CARACTERIZAÇÃO DOS PESCADORES E DOS CUSTOS DA FROTA}

Para caracterizar a pesca comercial da região do rio Purus, foram feitas entrevistas com os pescadores dos municípios de Sena Madureira, Manoel Urbano e Boca do Acre. Nesses municípios, as entrevistas foram feitas durante os meses de outubro e novembro de 2005, com pescadores que desembarcaram seu pescado nos principais portos das cidades. Foi realizada uma entrevista por embarcação, totalizando 77 entrevistas. Do total de entrevistas, 47\% são com pescadores de Boca do Acre, 32\% de Sena Madureira e 21\% de Manoel Urbano; sendo que, do total entrevistado em Boca do Acre, $57 \%$ correspondem a barcos de pesca e 43\% a canoas motorizadas. Em Sena Madureira, 88\% da amostra corresponde a canoas motorizadas e $12 \%$ a barcos de pesca; em Manoel Urbano, a pesca é praticada principalmente por canoa, sendo que $94 \%$ da amostra local corresponde à canoa motorizada e $6 \%$ a canoas sem motor. As entrevistas enfocaram questões sobre a idade, a escolaridade número de filhos e a renda recebida pelas famílias. Também foram feitas perguntas referentes às atividades 
econômicas praticadas pelo pescador, como cultivos agrícolas, criação de gado, além de informações gerais da atividade pesqueira. Em cada entrevista também foram coletados dados da última viagem de pesca, com perguntas direcionadas ao custo de viagem, material de pesca e mão de obra, além de perguntas sobre a comercialização do pescado. A estrutura de custos de cada viagem de pesca foi elaborada a partir dessa amostra e expandida para o ano, a partir da sazonalidade mostrada pela estatística pesqueira de 2004.

A rentabilidade da viagem de pesca foi calculada a partir do volume capturado e vendido, deduzidas as despesas com a compra do gelo, combustível, alimentação, material para conserto de arreio e depreciação da embarcação, canoas utilizadas e arreios. A eficiência econômica dos barcos foi calculada como a relação entre despesas e renda.

Para calcular a sazonalidade foram utilizados dados mensais médios da SEATER, para cada tipo de embarcação em cada cidade estudada (Sena Madureira, Manoel Urbano e Boca do Acre). Ainda com a base de dados da SEATER foi calculada renda e a produção média por viagem de pesca e o preço médio para cada mês. Foram utilizados os dados de custos, separando em custos variáveis por quilo, com base nos dados da amostra de pescadores, e então expandidos para os demais meses, tendo como referência o volume capturado. Os custos variáveis foram somados ao custo fixo, para se obter o custo total da viagem de pesca.

\section{RESULTADOS}

\subsection{CARACTERIZAÇÃO DA REGIÃO DO ALTO PURUS}

O estado do Acre está situado no sudoeste da Região do Norte do Brasil, com uma área de mais de 153 mil $\mathrm{km}^{2}$ e divide-se em cinco regiões de desenvolvimento: Alto Acre, Baixo Acre, Purus, Tarauacá/Envira e Juruá. A ocupação do estado foi feita principalmente pelos nordestinos, no final do século XIX, os quais subiram os rios Purus e Juruá, ultrapassando os limites estabelecidos pelo Tratado de Madri. Com o declínio da borracha, o Acre sofreu um esvaziamento demográfico, passando de 93 mil nos anos 1920, para $80 \mathrm{mil} \mathrm{em}$ 1940. Em 1980, a população acreana era de aproximadamente 300 mil habitantes e tinha a menor taxa de crescimento do país (CORREIA, 1999). O estado do Acre ainda tem sua economia baseada no extrativismo, sendo o primeiro produtor 
nacional de borracha e o terceiro de castanha-do-pará. A introdução da atividade agrícola no estado do Acre ocorreu tardiamente, em função da exploração do espaço estar voltado para o extrativismo da borracha.

Em 1970, foi instalada uma política pecuarista para o estado, sob o slogan "Produzir no Acre, investir no Acre e exportar pelo Pacífico" (CORREIA, 1999). Esta política beneficiava os fazendeiros, mas trazia prejuízo para os seringueiros e posseiros, que migraram para as cidades. Atualmente, a pecuária, embora esteja ocupando as terras do estado, tem se tornado inviável, devido à falta de estradas para escoar a produção. Ainda nos anos 1970, o Instituto Nacional de Colonização e Reforma Agrária (INCRA) e a Empresa de Assistência Técnica e Extensão Rural (EMATER) reorganizaram a agricultura regional, implantando núcleos de colonização do Projeto de Assentamento Dirigido (PADs), incentivando o plantio de culturas permanentes, além daquelas destinadas à subsistência (CORREIA, 1999), baseada no cultivo de mandioca, arroz, milho e feijão.

O estado Acre ainda hoje apresenta uma grande dificuldade de contato com o resto do país, visto que os principais meio de transporte são principalmente os barcos, mas os rios só podem ser navegados em épocas de cheias, como ocorre no Purus. Em função disso, os principais portos que escoam a produção acreana situam-se no estado do Amazonas, como o município de Boca do Acre, para a bacia do rio Purus; e Eirunepé, para a bacia do Juruá. As principais estradas do estado são a BR-364, que liga Rio Branco, capital do estado, às principais cidades do estado; e a BR-317, que liga Rio Branco ao município de Boca do Acre, no estado do Amazonas, tendo sido recentemente asfaltada a conexão com Porto Maldonado e Cusco (Peru).

O rio Purus, foco deste trabalho, é um afluente da margem direita do rio Amazonas, com nascente no Peru e é o segundo rio em termos de área de drenagem do estado. É um rio sinuoso e com lagos formados por segmentos do rio que foram isolados no passado (meandros abandonados). Nesses lagos ocorrem atividades significativas de pesca, que aliadas à pesca em rios, fornecem uma importante fonte de alimentação e renda para os habitantes da região. A Figura 1 mostra a área de estudo, onde os municípios pesquisados têm influencia direta do rio Purus e de seus afluentes, submetendo-se às variáveis inerentes aos cursos d'água (SILVA, 2008, 2009). 
Figura 1: Área do estudo - municípios pesquisados - bacia do rio Purus, estados do Acre e do Amazonas, Brasil.

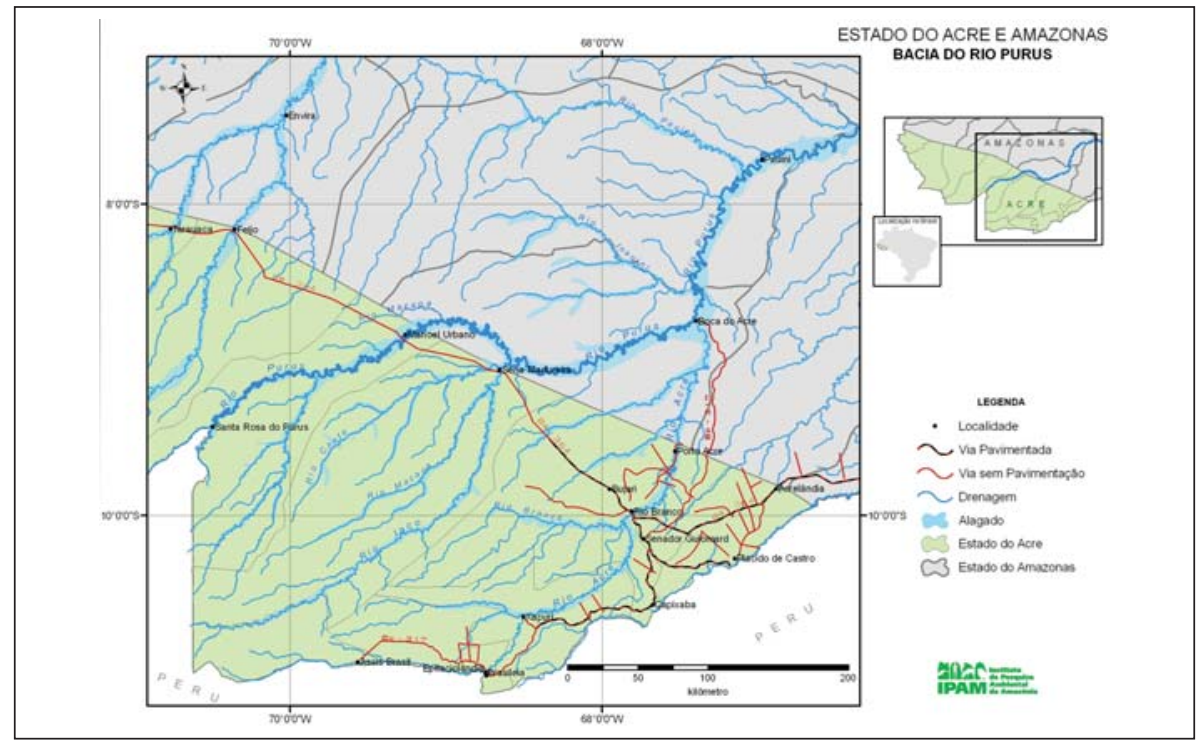

Fonte: Instituto de Pesquisa Ambiental da Amazônia.

\subsection{CARACTERIZAÇÃO DA FROTA PESQUEIRA NO ALTO PURUS}

A base de dados do Projeto Alto Purus possui registro de mais de 200 embarcações nos municípios de Manoel Urbano, Sena Madureira e Boca do Acre. Com base em 2004, a maioria das embarcações são de canoas motorizadas e barcos de pesca. Mais de $80 \%$ da frota de Manoel Urbano e mais de $70 \%$ da frota de Sena Madureira são compostas por canoa a motor. Em Boca de Acre, a relação é inversa - com mais de $90 \%$ da frota composta de barco pescador, indicando um maior mercado local e uma maior incidência de pescadores comerciais intensivos. A maior importância da frota comercial em Boca do Acre se deve ao fato do desembarque desta cidade não só abastecer o mercado local, mas também a capital do Acre, que se localiza a aproximadamente $200 \mathrm{~km}$ de distância.

Dessas três cidades, Boca do Acre é o principal mercado e ponto de desembarque responsável por mais de $70 \%$ do desembarque total dos três municípios; já Sena Madureira é de tamanho intermediário, recebendo um volume de 14 mil quilos, enquanto Manoel Urbano se caracteriza como um mercado muito pequeno, onde desembarcam menos de 10 mil quilos do total desembarcado. A Tabela 1 mostra que a maior parte do desembarque pesqueiro é feita por barco pescador, representando $81 \%$ do total, sendo $11 \%$ é feito por 
canoas e $8 \%$ referente a barco comprador, sendo que barcos mistos ou outros tipos de embarcação não tiveram registros. Manoel Urbano, onde desembarcam 88 barcos durante o ano, apesar de ser um mercado menor que de Boca do Acre, caracteriza-se pela maior diversificação da frota, apresentando desembarque de pescado de barco misto, barco pescador, canoa sem motor e canoa a motor. Boca do Acre apresenta desembarque somente de barco comprador, barco pescador e canoa motor (Tabela 1).

Tabela 1: Desembarque por tipo de embarcação nos municípios (\% de quilos), Alto Purus.

\begin{tabular}{l|c}
\hline \multicolumn{1}{c|}{ Tipo de Embarcação } & Total \\
\hline Barco Pescador & $81 \%$ \\
\hline Canoa Motor & $11 \%$ \\
\hline Barco Comprador & $8 \%$ \\
\hline Barco Misto & $0 \%$ \\
\hline Canoa & $0 \%$ \\
\hline Barco Carga & \\
\hline Total & $100 \%$ \\
\hline
\end{tabular}

Fonte: Estatística Pesqueira SEATER/AC.

Em relação aos ambientes, a maior parte (77\%) da captura em Boca do Acre acontece no rio e o restante nos lagos. Nesse município, há maior variedade de uso de arreio, sendo a maior parte capturada por múltiplos arreios e o restante principalmente por rede de lance e malhadeira. Em relação às espécies capturadas, em Boca do Acre predomina o filhote (Brachyplatystoma filamentosum), o jandiá (Leiarius marmoratus), o surubim (Psendoplatystoma tigrinum), o mandi (Pimelodus cf. altipinnis), o pacu (Mylossoma durivente) e a branquinha (Potamorbina latior) que somam $77 \%$ do total de toneladas desembarcadas no município.

Sena Madureira possui uma relação similar a Boca do Acre, com 68\% da captura ocorrendo no rio, 21\% em lagos e o restante em igapó e igarapé. Em Sena Madureira, a captura é dividida entre malhadeira (64\%), dois ou mais arreios conjugados (18\%) e com rede de lance (4\%), onde as espécies mais comercializadas são a branquinha-comum (Potamorbina latior), o jandiá (Leiarius marmoratus), o filhote (Brachyplatystoma filamentosum), o bagre, o mandi (Pimelodus cf. altipinni), e a curimatá (Prochilodus nigricans), que corresponde a 69\% do total de pescado desembarcado no município, em 2004.

Em relação a arreios de pesca, $51 \%$ da pesca é feita com aparelhos múltiplos, mas quase todo o pescado é capturado com malhadeira (27\%), seguida de rede de lance $(18 \%)$ (Tabela 2). A malhadeira é usada nas três cidades, enquanto a rede de lance é utilizada somente em Sena Madureira e Boca do Acre. 
Tabela 2: Total da captura por tipo de arreio nos municípios, Alto Purus, 2004.

\begin{tabular}{l|r|r}
\hline \multicolumn{1}{c|}{ Tipo de Arreio } & Total & $\mathbf{\%}$ \\
\hline Vários & 86.464 & $51 \%$ \\
\hline Malhadeira & 45.474 & $27 \%$ \\
\hline Rede de Lance & 31.054 & $18 \%$ \\
\hline Espinhel & 900 & $1 \%$ \\
\hline Outros & 2.505 & $1 \%$ \\
\hline Indeterminado & 2.125 & $1 \%$ \\
\hline Total & $\mathbf{1 6 8 . 5 2 2}$ & $\mathbf{1 0 0 \%}$ \\
\hline
\end{tabular}

Fonte: Estatística Pesqueira, SEATER/AC.

Em Manoel Urbano, quase toda produção desembarcada é oriunda dos lagos (94\%), onde aproximadamente a totalidade da captura é feita com malhadeira (96\%). As principais espécies capturadas foram filhote e branquinha e as espécies mais comercializadas em 2004 foram: branquinha-cascuda (Psectrogaster rutiloides), bacu (Lithodoras dorsalis), saúna (hemiodus sp.) e curimatá (Prochilodus nigricans) (Tabela 3).

Tabela 3: Total de toneladas desembarcadas (em \%) nos principais portos dos municípios estudados, por espécie.

\begin{tabular}{l|c}
\hline \multicolumn{1}{c|}{ Espécie } & $\%$ \\
\hline Filhote/Piraíba & $29 \%$ \\
\hline Branquinha & $11 \%$ \\
\hline Jandiá & $10 \%$ \\
\hline Mandi & $8 \%$ \\
\hline Surubim & $6 \%$ \\
\hline Pacu & $6 \%$ \\
\hline Jaú/Pacamum & $4 \%$ \\
\hline Curimatã & $4 \%$ \\
\hline Piramutaba & $3 \%$ \\
\hline Bagre & $2 \%$ \\
\hline Dourada & $2 \%$ \\
\hline Salada & $2 \%$ \\
\hline Tucunaré & $2 \%$ \\
\hline Mapará & $2 \%$ \\
\hline Outros & $9 \%$ \\
\hline Total & $\mathbf{1 0 0} \% \mathbf{( 1 9 8 , 6 )}$ \\
\hline
\end{tabular}

Fonte: Estatística Pesqueira SEATER/AC. 


\subsection{CARACTERIZAÇÃO DO PESCADOR}

Para caracterizar o pescador comercial, os dados foram agrupados por município para mostrar o perfil do pescador em cada cidade. O levantamento socioeconômico mostrou que o pescador comercial nos municípios de Sena Madureira e Manoel Urbano possui idade média de 39 anos, sendo que em Boca do Acre a média de idade é de 44 anos. O número de filhos não variou nos três municípios, sendo a média de 5 filhos por família. O município de Boca do Acre apresentou um nível de escolaridade mais baixo, em média, de 2 anos de estudo; e em Sena Madureira e Manoel Urbano, em média, de 5 anos de escola.

Em relação às atividades econômicas exercidas pelos pescadores de Sena Madureira, 50\% sempre trabalharam com a pesca, 29\% eram agricultores e $21 \%$ eram seringueiros. Em Boca do Acre, 81\% dos entrevistados sempre foram pescadores, sendo que apenas 19\% praticaram outras atividades. Em Manoel Urbano, o pescador comercial praticou diversas outras atividades antes de ser pescador,sendo que as principais foram como agricultor $(31 \%)$ e seringueiro (25\%). Em Sena Madureira e Manoel Urbano mais da metade dos pescadores plantam (52\% - 63\%, respectivamente), e quase 50\% dos pescadores de Sena Madureira criam gado (Tabela 4).

Tabela 4: Perfil do pescador comercial por município estudado, Alto Purus.

\begin{tabular}{lccc}
\hline \multicolumn{1}{c}{ Perfil do Pescador } & $\begin{array}{c}\text { Manoel } \\
\text { Urbano }\end{array}$ & $\begin{array}{c}\text { Sena } \\
\text { Madureira }\end{array}$ & $\begin{array}{c}\text { Boca do } \\
\text { Acre }\end{array}$ \\
\hline Média de idade do entrevistado & 39 & 38 & 44 \\
Média de escolaridade (anos de estudo) & 5 & 5 & 2 \\
Percentual de pescadores analfabetos & & $28 \%$ & $21 \%$ \\
Média do número de filhos & 5 & 5 & 6 \\
Profissão anterior & & & \\
Sempre foi pescador & & $50 \%$ & $81 \%$ \\
Agricultor & $31 \%$ & $29 \%$ & $8 \%$ \\
Seringueiro & $25 \%$ & $21 \%$ & $6 \%$ \\
Outros & $44 \%$ & & $5 \%$ \\
\hline
\end{tabular}

\subsection{CARACTERÍSTICAS DA PESCA NA REGIÃO DO ALTO PURUS}

Na região do Alto Purus predomina a pesca de rio, que é praticada pelos pescadores durante quase todo o ano. Somente durante os meses de novembro 
a fevereiro há uma redução do número de pescadores, período em que ocorre o defeso de algumas espécies para reprodução.

$\mathrm{Na}$ área do município de Manoel Urbano, a pesca é praticada com mais frequência nos lagos. Os principais locais de pesca são o lago Bela Vista (27\%), lago Bananal (20\%), lago Santarém (16\%) e lago Novo (9\%). Durante o verão, o nível das águas do rio Purus é bastante baixo e não permite o acesso das embarcações de pesca ao município. Em Sena Madureira, a pesca é praticada principalmente nos rios Purus (51\%) e Iaco (13\%) e 14\% das pescarias são praticadas em lagos. Em Boca do Acre a pesca é praticada principalmente no rio Purus, em diversos pontos do rio, próximo à área dos municípios de Pauiní e Lábrea, no estado do Amazonas (68\%). No verão, pescadores de Sena Madureira que possuem barco a motor desembarcam o pescado na cidade de Boca do Acre. Por outro lado, a cidade de Boca do Acre apresenta o maior número de barcos de pesca e maior quantidade de quilos desembarcados, sendo responsável pelo abastecimento de outros mercados, como de Rio Branco e Sena Madureira, no período da seca.

As pequenas embarcações, como as canoas motorizadas de Sena Madureira ou de Manoel Urbano, em geral pescam dentro da área do município. Já os barcos, atuam principalmente na região dos municípios de Lábrea e Pauiní, no estado do Amazonas ou em áreas próximas de Boca do Acre.

O perfil das embarcações não variou entre os municípios estudados, no entanto, em Sena Madureira e Manoel Urbano predomina a pesca de canoas motorizadas, enquanto que em Boca do Acre a maior parte dos pescadores pesca com barco a motor. Em razão disso, o perfil da frota pesqueira foi separado por tipo de embarcação de pesca e não por município de origem. As canoas motorizadas têm em média $9 \mathrm{~m}$ de comprimento e capacidade de gelo média em torno de 480 quilos. O valor médio das canoas, incluindo o motor, é em torno de $\mathrm{R} \$ 2.600,00$ e vida útil de cinco anos. Os barcos de pesca têm tamanho médio de 12 m e capacidade de gelo de 900 quilos. O valor médio da embarcação é de $\mathrm{R} \$ 12.000,00$ e durabilidade de 10 anos.

A malhadeira é o principal arreio dos pescadores, sendo que os pescadores de canoa possuem em média 4 malhadeiras, enquanto que de barcos possuem média de 9 malhadeiras. O tamanho médio das malhadeiras é de $100 \mathrm{~m}$ de comprimento e, em menor escala, os pescadores também possuem tarrafas e espinhel (Tabela 5). 
Tabela 5: Principais arreios utilizados pelos entrevistados por tipo de embarcação.

\begin{tabular}{l|r|r|r|r|r|r}
\hline \multirow{2}{*}{$\begin{array}{c}\text { Principais arreios } \\
\text { utilizados }\end{array}$} & \multicolumn{3}{|c|}{ Canoa motor } & \multicolumn{3}{c}{ Barco motor } \\
\cline { 2 - 7 } & $\mathbf{0}$ & Qtd. & $\begin{array}{c}\text { Tamanho } \\
\text { (metro) }\end{array}$ & \multicolumn{1}{c}{$\%$} & \multicolumn{1}{c}{ Qtd. } & $\begin{array}{c}\text { Tamanho } \\
\text { (metro) }\end{array}$ \\
\hline Malhadeira (metros) & $98 \%$ & 4 & 103,3 & $91 \%$ & 9 & 114,8 \\
\hline Tarrafa (crescido) & $2 \%$ & & & $6 \%$ & 4 & 31 \\
\hline Espinhel (anzóis) & & & & $3 \%$ & 5 & 50 \\
\hline
\end{tabular}

\subsection{ANÁLISE ECONÔMICA DA ATIVIDADE PESQUEIRA}

A análise econômica da atividade pesqueira dos diferentes tipos de barcos de pesca enfoca quatro questões: a) a estrutura de custos e renda do barco pescador, b) a relação entre o tipo de embarcação e a renda dos pescadores, c) a eficiência econômica da atividade pesqueira; d) a geração de renda e emprego da frota pesqueira de Sena Madureira, Manoel Urbano e Boca do Acre.

\subsection{ESTRUTURA DE CUSTOS E A RENDA DO BARCO DE PESCA}

Para calcular os custos foram consideradas as despesas com mão de obra, gelo, combustível, alimentação, depreciação do barco, depreciação dos arreios e custos de manutenção do motor e da embarcação. Para os barcos, o custo da mão de obra corresponde a $41 \%$ do valor total da receita, sendo o segundo maior custo com a compra do combustível (18\%); o custo com gelo representa $10 \%$ da receita, seguido da compra de alimentação. Os custos com depreciação somam $14 \%$ da receita total do barco, sendo a depreciação dos arreios responsável por quase $40 \%$ do valor total da depreciação e $6 \%$ do valor da receita. Isto ocorre devido ao grande número de arreios e ao alto valor desses equipamentos. A depreciação do barco corresponde a $3 \%$ do valor da receita e manutenção do motor, calafeto e lubrificação a 5\% da receita do barco.

Para as canoas, a estrutura de custos é similar a de barcos, em que o custo de mão de obra é o mais relevante, representando 38\% dos custos totais, seguido de combustível (13\%), gelo (7\%) e alimentação (5\% da receita). Os custos com depreciação do arreio correspondem a $17 \%$ do total da receita; assim como para barcos, a depreciação dos arreios é a mais relevante, correspondendo a 28\% dos custos totais de depreciação e 5\% do valor da receita, seguidos dos custos da depreciação da canoa (4\%) e motor (2\%) (Tabela 6). 
Tabela 6: Percentual e valor médio dos custos de viagem e custos de depreciação e manutenção da embarcação de pesca.

\begin{tabular}{|c|c|c|c|}
\hline Custos & $\%$ da receita & $\begin{array}{c}\text { Média } \\
(\mathrm{R} \$ 1)\end{array}$ & $\%$ da receita \\
\hline Custos variáveis & Canoa $(n=54)$ & \multicolumn{2}{|c|}{$\operatorname{Barco}(n=23)$} \\
\hline Mão de obra & $38 \%$ & & $41 \%$ \\
\hline Combustível & $13 \%$ & & $18 \%$ \\
\hline Gelo & $7 \%$ & & $10 \%$ \\
\hline Alimentação & $5 \%$ & & $7 \%$ \\
\hline Subtotal & $63 \%$ & & $76 \%$ \\
\hline Subtotal $(\mathrm{R} \$)$ & 229,92 & & $2.125,94$ \\
\hline \multicolumn{4}{|l|}{ Custos fixos } \\
\hline Depreciação da embarcação & $4 \%$ & & $3 \%$ \\
\hline Depreciação do arreio & $5 \%$ & & $6 \%$ \\
\hline Manutenção motor & $2 \%$ & & $2 \%$ \\
\hline Lubrificação & $2 \%$ & & $2 \%$ \\
\hline Pintura & $2 \%$ & & $0 \%$ \\
\hline Calafeto & $2 \%$ & & $1 \%$ \\
\hline Subtotal & $17 \%$ & & $14 \%$ \\
\hline Subtotal $(\mathrm{R} \$)$ & 60,45 & & 404,47 \\
\hline Receita por viagem & 365,74 & & $2.792,37$ \\
\hline Total dos custos por viagem & 290,37 & & $2.530,41$ \\
\hline Captura media por viagem $(\mathrm{kg})$ & 110 & & 766 \\
\hline Preço médio $(\mathrm{R} \$ 1)$ & 3,32 & & 3,65 \\
\hline Lucro $(\mathrm{R} \$)$ & 75,37 & & 261,96 \\
\hline
\end{tabular}

Com base nos dados da última viagem de pesca, foram estimados os custos da viagem e a renda média do pescador, por mês e por ano. Os barcos fazem, em média, 2 viagens por mês, com duração total de 21 dias, sendo que 6 dias são gastos na viagem (ida e volta) e 12 dias na pescaria, em que a média de canoas por barco de pesca é de 1,4 canoas e 5 pescadores por viagem.

Os custos da viagem incluem despesas com combustível, gelo, alimentação e mão de obra, somando o valor de $\mathrm{R} \$ 4.159,34$ por mês, que corresponde a $76 \%$ da receita total do barco. A captura média mensal é de 1.498 quilos e a renda bruta dos barcos foi estimada em $\mathrm{R} \$ 5.463,63$. Deduzidos os custos da viagem de pesca, a renda média por barco motor é de $\mathrm{R} \$ 512,64$ por mês.

As canoas motorizadas correspondem a 69\% das embarcações de pesca. Os pescadores dessas canoas realizam, em média, 5,3 viagens por mês, com duração total de 6 dias, 2,6 dias gastos em viagem. A pesca envolve apenas uma canoa e 2 pescadores, e a captura média é de 583 quilos de pescado por mês, com receita do pescador de canoa de aproximadamente $\mathrm{R} \$ 1.937,07$ por mês. 
O custo médio mensal da viagem é de $\mathrm{R} \$ 1.537,91$, correspondendo a $63 \%$ da receita total, sendo que a renda líquida mensal do pescador de canoa a motor é de $\mathrm{R} \$ 339,16$.

\subsection{RELAÇÃO ENTRE O TIPO DA EMBARCAÇÃO E A RENDA DOS PESCADORES}

A segunda questão desta análise é a relação entre a renda do pescador e o tipo de embarcação, onde o pagamento do pescador é o principal custo da viagem de pesca, tanto para a pesca de canoa quanto para a pesca de barco. A divisão da renda da pescaria toma diversas formas conforme o tipo de embarcação e município. Por exemplo, em Manoel Urbano, onde a pesca é basicamente de canoas, com um ou dois pescadores, a divisão da renda quase sempre é feita em partes iguais, onde os pescadores também dividem os custos da viagem de pesca.

Em Sena Madureira, onde 77\% das embarcações correspondem a canoas (Tabela 1), o sistema de divisão de renda quase sempre é feito como em Manoel Urbano, em que apenas $10 \%$ dos pescadores de canoas e todos pescadores de barcos recebem em média $35 \%$ da renda da pesca.

O pagamento do pescador no município de Boca do Acre é baseado na produção individual, pois, entre os entrevistados, 69\% de canoas e $84 \%$ de barcos pagam metade do preço de venda do pescado capturado pelo pescador. Em menor escala, outros pagam 35\% da renda da pesca e outros ainda utilizam outra forma de pagamento para o pescador.

Com foi visto anteriormente, o pagamento do pescador é o principal custo da viagem de pesca, variando de 38 a 41\% do custo total. Em Manoel Urbano, onde a pesca é basicamente feita com canoa a motor e para abastecer um mercado pequeno, a divisão da renda é feita igualmente entre o dono da canoa e o pescador auxiliar. Nas duas outras cidades, Sena Madureira e Boca do Acre, a divisão da renda é feita basicamente por meio do pagamento de uma percentagem do preço ou da produtividade.

$\mathrm{Na}$ pesca de canoa, o valor da mão de obra é de $\mathrm{R} \$ 732,00$, com dois pescadores. Neste caso, cada pescador recebe $\mathrm{R} \$ 366,00$ por mês e, em se tratando dos barcos, o valor pago é de $\mathrm{R} \$ 2.229,00$ com a participação de 5 pescadores, correspondendo a uma renda de $\mathrm{R} \$ 446,00$ por mês, por pescador. Na região estudada, o pescador de canoa obtém uma renda de $22 \%$ a mais que o salário mínimo, enquanto o pescador de barco recebe uma renda $49 \%$ a mais que o salário mínimo, para a época em que foi realizada a pesquisa. 
Considerando o número de embarcações da base de dados da estatística pesqueira da SEATER (Tabela 1) e o número médio de pescadores por tipo de embarcação, pode-se estimar o valor total pago pela mão de obra na área de estudo. Um total de 119 canoas a motor desembarcou pescado nos municípios de Sena Madureira, Manoel Urbano e Boca do Acre, gerando uma renda de aproximadamente R\$ 1 milhão de reais, enquanto 89 barcos geraram uma renda de $\mathrm{R} \$ 2,4$ milhões, somando a um total de $\mathrm{R} \$ 3,3$ milhões pagos com mão de obra de pescador.

\subsection{EFICIÊNCIA ECONÔMICA}

A terceira questão desta análise é a eficiência relativa das diferentes categorias de pescadores. A captura por unidade de esforço (CPUE) medida em termos de quilos capturados por pescador por dia, mostrou-se distinta entre os tipos de barcos, conforme o tipo de embarcação de pesca utilizado. As canoas apresentaram um CPUE igual a $11 \mathrm{~kg} /$ pescador/ano; as canoas a motor apresentaram CPUE um pouco maior, de $13.87 \mathrm{~kg} /$ pescador/dia, enquanto que os barcos apresentaram CPUE de $7,57 \mathrm{~kg} /$ pescador/dia. Contudo, quando se calcula o intervalo de confiança, essa diferença não é observada, como pode ser visto na Tabela 7 , onde todos os tipos de embarcações mostram a mesma produtividade.

Tabela 7: CPUE (kg por pescador por dia) por embarcação, Purus.

\begin{tabular}{l|c|c|r|r}
\hline Embarcação & CPUE & $\begin{array}{c}\text { Desvio } \\
\text { Padrão }\end{array}$ & $\begin{array}{c}\text { Intervalo de } \\
\text { confiança inferior }\end{array}$ & \multicolumn{2}{|c}{$\begin{array}{c}\text { Intervalo de } \\
\text { confiança superior }\end{array}$} \\
\hline Barco Pescador & 7,57 & 7,98 & $-6,48$ & 8,66 \\
\hline Canoa & 11,28 & 1,80 & $-8,78$ & 13,77 \\
\hline Canoa Motor & 13,87 & 11,80 & $-12,38$ & 15,36 \\
\hline
\end{tabular}

A análise de eficiência econômica, entretanto, mostra uma situação diferente. Do ponto de vista econômico, a eficiência econômica medida em termos de custo investido mostra que as canoas apresentaram eficiência econômica de 1,26, ou seja, para cada 1 real investido a canoa motor tem uma renda de $\mathrm{R} \$ 1,26$. No caso dos barcos motor, para cada 1 real investido, o barco tem uma renda de $\mathrm{R} \$ 1,1$. 


\section{CONSIDERAÇÕES FINAIS}

A pesca na região do Alto Purus tem um papel importante para as famílias que vivem às margens do rio Purus e seus afluentes, bem como para a economia nos centros urbanos. A pesca é praticada o ano todo, por quase todos os pescadores entrevistados (91\%), onde a frota pesqueira na região é formada principalmente por pequenas embarcações do tipo canoas motorizadas, nos municípios de Sena Madureira e Manoel Urbano, enquanto que em Boca do Acre a frota pesqueira é mais diversificada, composta principalmente por barcos a motor e canoas motorizadas.

O perfil do pescador não variou nos municípios em relação à idade, escolaridade, composição familiar ou à renda, no entanto, pescadores de Sena Madureira e Manoel Urbano praticam outras atividades econômicas, como pecuária e agricultura, enquanto que em Boca do Acre o pescador dedica-se quase que exclusivamente à pesca. Em Boca do Acre, quase todos os pescadores sempre trabalharam com a pesca; já em Sena Madureira e Manoel Urbano, os pescadores exerciam, antes da pesca, outras atividades, principalmente como agricultores ou seringueiros.

As famílias dessa região recebem também, em média, outros dois tipos renda, sendo que os principais são seguro desemprego de pescador e bolsa família. O seguro desemprego é pago para pescador uma vez por ano, no valor médio de R \$1.107,00; e os benefícios do governo, como bolsa escola ou bolsa família, correspondem ao valor médio anual de $\mathrm{R} \$ 986,00$. Rendas provenientes de aposentadoria e salários são menos frequentes entre os pescadores, pois em Boca do Acre 18\% dos entrevistados recebem aposentadoria e possuem renda média anual de $R \$ 3.877,00$. A renda de salário é, em média, de $R \$ 5.340,00$ por ano, porém, poucas famílias de Sena Madureira e de Boca do Acre possuem essa renda. Em Manoel Urbano nenhum pescador entrevistado recebe salário.

Em relação à atividade de pesca, os municípios de Sena Madureira, Manoel Urbano e Boca do Acre apresentam, ao mesmo tempo, diferenças em alguns pontos e semelhanças em outros. Em relação ao ambiente de pesca, em Manoel Urbano predomina a pesca de lagos, enquanto que Sena Madureira os ambientes de pesca são mais diversificados, com registros de pesca em lagos, rios e igarapés. Em Boca do Acre predomina a pesca no rio Purus, principalmente na área dos municípios de Pauiní e Lábrea.

Quanto ao tipo de embarcação utilizada, Manoel Urbano apresenta um perfil diferente dos demais. Nesse município a pesca é praticada somente em canoas, sendo que um pequeno percentual corresponde a canoas sem motor, 
enquanto que em Sena Madureira a maioria dos pescadores pesca de canoas e alguns utilizam barco a motor. Em Boca do Acre, a pesca é praticada basicamente de barcos, sendo menor o número de canoas motorizadas. Em relação aos custos da viagem, a análise mostrou que os custos variáveis (alimentação, gelo, combustível e mão de obra) representam $63 \%$ da receita dos pescadores de canoa e $76 \%$ da receita total dos barcos de pesca. Os custos fixos variaram de $6 \%$ a $1 \%$ da receita para barcos, e de $2 \%$ a $5 \%$ da receita total das canoas, sendo a depreciação dos arreios responsável pela maior parte dos custos de depreciação. Pescadores de canoa motorizada apresentaram maior capacidade produtiva por unidade de esforço, em relação aos pescadores de barcos.

Em relação aos arreios utilizados na pescaria, em Manoel Urbano a pesca de malhadeira é o arreio mais usado; já em Sena Madureira e Boca do Acre há uma maior variação dos arreios de pesca. Nesses dois municípios também ocorre a pesca com redinha, o que não acontece em Manoel Urbano. As espécies capturadas em Manoel Urbano e Sena Madureira apresentaram uma grande variedade de espécies de escama, enquanto que em Boca do Acre as espécies de couro são mais frequentes. O pescado quase sempre é comercializado no próprio município, no entanto, em Manoel Urbano e em Sena Madureira a produção é vendida no mercado ou direto ao consumidor, no caso de Manoel Urbano, onde não há mercado de peixe. Em Boca do Acre, $89 \%$ dos pescadores vendem pescado para atravessadores e a produção abastece o mercado de Rio Branco e parte do pescado é destinada ao mercado de Sena Madureira, principalmente no período da seca, quando os barcos de Sena Madureira não chegam ao porto, devido o baixo nível do rio.

A comercialização ocorre principalmente nos mercados municipais, com exceção do município de Manoel Urbano. Assim como em Sena Madureira, o município de Boca do Acre possui apenas um mercado, porém, com o dobro do número de bancas de pescado. Os vendedores de pescado geralmente trabalham sozinhos nas bancas e possuem vários anos de experiência na comercialização, onde o volume de pescado comercializado por banca em Sena Madureira representa mais que o dobro do volume comercializado por banca no mercado de Boca do Acre. Isto ocorre porque o pescado desembarcado em Boca do Acre abastece o mercado de Rio Branco. O preço médio de venda do pescado em Sena Madureira também é mais alto que em Boca do Acre. O período de safra em cada cidade é de três meses, enquanto que a entressafra dura em média oito meses. Recomendamos, a partir deste estudo, uma análise de eficiência econômica da frota pesqueira, com base em dados coletados em período de pico da pesca na região, uma vez que a amostra deste estudo é baseada em entrevistas realizadas em um período crítico de seca na região, e ao final do período de pesca. 


\section{REFERÊNCIAS}

ALMEIDA, O.; MCGRATH, D. G.; RUFFINO, M. L. The commercial fisheries of the lower Amazon: an economic analysis. Fisheries Management and Ecology, v. 8, p. 253-269, 2001.

ALMEIDA, O.; LORENZEN, K.; MCGRATH, D. G. Commercial fishing in the Brazilian Amazon: regional differentiation of fleet characteristics and economic efficiency. Fisheries Management and Ecology, v.10, p. 109-115, 2003.

ALMEIDA, O.; LORENZEN, K.; MCGRATH, D. G. Commercial fishing sector in the regional economy of the brazilian Amazon. In: WELCOMME, R.; PETER, T. (Orgs.). Proceedings of the Second International Symposium on the Management of Large Rivers for Fisheries. Bangkok: FAO-Regional Office for Asia and the Pacific/RAP Pulication, 2004. p. 15-24. v. 2.

ALMEIDA, O.; LORENZEN, K.; MCGRATH, D. G. Fishing agreements in the lower Amazon: for gain and restraint. Fisheries Management and Ecology, v. 16, p. 61-67, 2009.

CORREIA, R. Geografia do Acre. Apostila Pre-Vestibular Ideal, 2009. Disponível em: <http://www.miniweb.com.br/Geografia/Artigos/geologia. htm>. Acesso em: 3 out. 2005.

D'ALMEIDA, B.G. Os acordos de pesca na Amazônia: uma perspectiva diferenciada de gestão das águas. In: ENCONTRO PREPARATÓRIO DO CONSELHO NACIONAL DE PESQUISA E PÓS-GRADUAÇÃO EM DIREITO - RECIFE, 15. 2006. Recife. Anais... Recife: CONPEDI, 2006.

EMBRAPA- Empresa Brasileira de Pesquisa Agropecuária. Sistema de Produção de gado e corte: Área de Abrangência do Sistema, 2003. Disponível em: <http:/ / sistemasdeproducao.cnptia.embrapa.br>. Acesso em: 17 out. 2005.

IBAMA-Instituto Brasileiro do Meio Ambiente e dos Recursos Naturais. Relatório estatístico da pesca, 1999. Brasília: Ibama, 2000.

Relatório estatístico da pesca, 2000. Brasília: Ibama, 2001.

IBGE-Instituto Brasileiro de Geografia e Estatística. Produção Agrícola Municipal - 2004. Disponível em: < http://www.sidra.ibge.gov.br/bda/pecua > Acesso em: 28 set. 2005.

MCGRATH, D. G. et al. Fisheries and evolution of resource management on the Lower Amazon floodplain. Human Ecology, v. 21, p. 167-195, 1993. 
RASEIRA, Marcelo Bassols. Monitoramento participativo dos acordos de pesca: como avaliar a captura de pescado. Manaus: IBAMA/ProVárzea, 2007. 24 p. Disponível em: <http://www.sepaq.pa.gov.br/files/u1/diag_ pesca2008.html>. Acesso em: 20 fev. 2009.

RUFFINO, M. L. Gestão do uso dos recursos pesqueiros na Amazônia. Manaus: IBAMA, 2005.

SILVA, C. N. Cartografia das percepções ambientais-territoriais dos pescadores do estuário amazônico com utilização de instrumentos de geoinformação. Revista Formação, Presidente Prudente, p.118-128, 2008.

O conceito de território nos estudos sobre pesca. In: SILVA, C. N. et al. Caminhos e lugares da Amazônia: Ciência, natureza e território. Belém: GAPTA/UFPA, 2009. p. 35-54. v.1.

SILVA, A. L.; BEGOSSI, A. Uso dos recursos por ribeirinhos no médio Rio Negro. In: BEGOSSI, A. (Org.). Ecologia de pescadores da Mata Atlântica e da Amazônia. São Paulo: HUCITEC, 2004. p. 89-148. 
